\title{
Bir Tıp Fakültesi'nde internlerin ve araştırma görevlisi hekimlerin çocuk hakları konusundaki bilgi, tutum ve davranışları
}

\author{
Knowledge, attitudes and behaviors of medical residents and interns about children's \\ rights
}

\author{
Ahmet Ergin, Betül Akbay, Rabia Melis Gündoğan
}

Özet

Amaç: Bu çalışma ile bir tıp fakültesinde son sınıf öğrencilerinin ve araştırma görevlisi hekimlerin çocuk hakları konusunda bilgi, tutum ve davranışlarının değerlendirilmesi amaçlanmıştır.

Gereç ve yöntem: Araştırmanın evrenini 323 kişi oluşturmaktadır. Örneklem seçilmeden evrenin tamamına ulaşılması hedeflenmiştir. Çalışma öncesinde etik kurul ve gerekli kurumsal izinler alınmıştır. Verilerin toplanmasında Çocuk Haklarına İlişkin Tutum Ölçeği'ni (ÇHTÖ) içeren anket formu kullanılmıştır. Ölçekten en az 22, en fazla 110 puan alınmakta; puanın yüksek olması olumsuz tutumu göstermektedir. On bir sorudan davranış puanı hesaplanmış olup; puanın artması sağlık hizmet sunumu sırasında çocuk haklarına yönelik olumlu davranışlar sergilendiğini göstermektedir (en az 11, en fazla 55). İstatistiksel anlamlılık düzeyi $p<0,05$ olarak kabul edilmiştir.

Bulgular: Çalışmaya 223 (\%69) kişi katılmıştır. Yaş ortalaması 26,8ะ3,0'dır. Yüzde 52,7'si erkek, \%62,8'i araştırma görevlisi hekimdir. Katılımcıların \%45'i Çocuk Haklarına Dair Sözleşme'yi (ÇHS) duymamıştır. ÇHTÖ puan ortalaması 29,8 $\pm 7,8$, çocuk haklarına ilişkin davranış puan ortalaması 46,2 $\pm 4,52$ 'dir. Araştırma görevlisi olmak ve ÇHTÖ'yü duymamak olumsuz tutum ve davranış için bağımsız risk faktörü olarak saptanmıştır.

Sonuç: Çocuk haklarına yönelik tutum ve davranış olumlu olmakla birlikte araştırma görevlisi hekimler intern hekimlere göre daha olumsuz tutum ve davranışa sahiptir. ÇHS'yi bilme durumu düşük olup, farkındalığın artırılması gerekmektedir.

Anahtar kelimeler: İnsan hakları, çocuk, sağlık personeli.

Ergin A, Akbay B, Gündoğan RM. Bir Tıp Fakültesi'nde internlerin ve araştırma görevlisi hekimlerin çocuk hakları konusundaki bilgi, tutum ve davranışları. Pam Tıp Derg 2020;13:303-310.

\begin{abstract}
Purpose: This study was aimed to evaluate the knowledge, attitudes and behaviors of interns and medical residents (MRs) regarding children's rights in a medical school.

Materials and methods: The universe of this study is 323 people. It was aimed to reach the whole universe without selecting the sample. Ethical committee and required permissions were obtained before the study. Data were collected by using a questionnaire including The Attitudes towards Children's Rights Scale. Minimum 22 points and maximum 110 points are obtained from the scale; high score indicates negative attitude. Behavior score was calculated from eleven questions. The increase in the score indicates that there are positive behaviors towards children's rights during the provision of health services (min.11, max.55). Statistical significance level was as accepted $p<0.05$.

Results: The sample consisted of 223 respondents. The mean age was $26.8 \pm 3.0,52.7$ percent of them are males and 62.8 percent of them are medical residents. $45 \%$ of the participants did not hear the Convention on the Rights of the Child (CRC). The mean of the attitude score was $29.8 \pm 7.8$. The mean of the behavior score was 46.2 \pm 4.52 . Being a MR and not to hearing about the Convention were independent risk factors for both negative attitudes and behaviors towards children's rights.

Conclusion: Although attitudes and behaviors towards children's rights are positive, medical residents have more negative attitudes and behaviors than interns. The awareness of the CRC is low and awareness should be increased.
\end{abstract}

Key words: Human rights, children, health personnel.

Ergin A, Akbay B, Gündoğan RM. Knowledge, attitudes and behaviors of medical residents and interns about children's rights. Pam Med J 2020;13:303-310.

Ahmet Ergin, Prof. Dr. Pamukkale Üniversitesi Tıp Fakültesi Halk Sağlığı Anabilim Dalı, Denizli, Türkiye, e-posta: aergin@pau.edu.tr (orcid. org/0000-0001-5236-7507)

Betül Akbay, Arş. Gör. Dr. Pamukkale Üniversitesi Tıp Fakültesi Halk Sağlığı Anabilim Dalı, Denizli, Türkiye, e-posta: betulakbayy@gmail.com (orcid.org/0000-0003-4424-2063) (Sorumlu Yazar)

Rabia Melis Gündoğan, Arş. Gör. Dr. Pamukkale Üniversitesi Tıp Fakültesi Halk Sağlığı Anabilim Dalı, Denizli, Türkiye, e-posta: melisgun93@ outlook.com (orcid.org/0000-0002-1608-6983) 


\section{Giriş}

"Çocuk Hakları", 18 yaş altındaki bireylerin haklarıdır ve çocukların erişkinlerden farklı fiziksel, fizyolojik ve psikolojik özellikleri olduğu ve sürekli büyüme ve gelişme göstermeleri nedeniyle, erişkinlere tanınan tüm hakların yanı sıra, çocuklara tanınan bazı özel hakları ifade etmektedir [1, 2].

Çocuk hakları, 1989 yılında Birleşmiş Milletler tarafından hazırlanan Çocuk Haklarına Dair Sözleşme (ÇHS) ile tanımlanmış, taraf devletlere bu haklara saygı gösterme, koruma ve yaşama geçirme yükümlülüğü getirilmiştir [2, 3]. Dünya genelinde hemen hemen tüm ülkelerin taraf olduğu bu sözleşmeyi, Türkiye 14 Eylül 1990'da imzalamış, 1995 yılında da onaylamıştır [2]. Çocuk hakları savunuculuğunda ÇHS ile ülkelere düşen sorumluluklar tanımlanmakla birlikte, toplumdaki tüm bireylerin de gerek günlük yaşamda gerekse iş yaşamında önemli sorumluluklar da yüklenmektedir. Sağlık çalışanları da meslekleri gereği çocukların sağlık ve iyilik halinin korunması ve geliştirilmesi sırasında çocuk haklarını dikkate almak durumundadır [4]. Bu kapsamda sağlık hizmetleri sunumunda ÇHS'ye uygun tutum ve davranışlara dikkat edilerek karar ve tedavi sürecine çocuğun katılımının sağlanması, çocuğun mahremiyetine dikkat edilmesi gibi uygulamalar tedaviye uyumu artırmakta iken, çocuk haklarına aykırı yapılan yanlış davranışlar çocuğun fiziksel ve psikolojik sağlığını olumsuz etkileyebilmektedir [4-6].

Sağlık personelinin çocuk haklarına saygıyı öngören tutum ve davranışları kazanabilmesi, kendi mesleki uygulamalarında dikkate alıp gözetebilmeleri için eğitim intiyacı bulunmakla birlikte tıp fakültesi eğitim müfredatlarında çocuk hakları eğitimi nadiren görülmektedir. Mevcut literatürde sağlık personelinde çocuk hakları ve uygulamaları ile ilgili bilgi birikimi kısıtıdır. Bu çalışma ile bir tıp fakültesinde öğrenim gören intern hekimlerin ve sağlık hizmeti sunmakta olan araştırma görevlisi hekimlerin çocuk hakları konusunda bilgi, tutum ve davranışlarının değerlendirilmesi amaçlanmıştır.

\section{Gereç ve yöntem}

Kesitsel tipteki bu araştırmanın evrenini 2017-2018 Eğitim Öğretim döneminde bir Tıp Fakültesi'nde öğrenim gören 116 intern hekim ile çocuk yaş grubundaki hastalara hizmet sunan veya uzmanlık döneminde çocuk hastaları olacak anabilim dallarında görevli 207 araştırma görevlisi hekim (Acil Tıp, Adli Tıp, Aile Hekimliği, Anestiziyoloji ve Reanimasyon, Beyin ve Sinir Cerrahisi, Çocuk Cerrahisi, Çocuk Sağlığı ve Hastalıkları, Çocuk ve Ergen Ruh Sağlığı ve Hastalıkları, Deri ve Zührevi Hastalıkları, Fizik Tedavi ve Rehabilitasyon, Göğüs Cerrahisi, Göz Hastalıkları, Kadın Hastalıkları ve Doğum, Kalp ve Damar Cerrahisi, Kulak Burun Boğaz Hastalıkları, Ortopedi ve Travmatoloji, Plastik ve Rekontstrüktif Cerrahi, Radyoloji, Üroloji Anabilim Dalları) olmak üzere toplam 323 kişi oluşturmaktadır. Araştırmada örneklem seçilmemiş olup evrenin tamamına ulaşılması hedeflenmiştir. Araştırmanın bağımlı değişkeni katılımcıların çocuk hakları konusundaki bilgi düzeyi, tutum ve davranışlarıdır. Bağımsız değişkenleri yaş, cinsiyet, araştırma görevlisi hekimlerin çalıştıkları anabilim dalı, meslekteki yılı, medeni durum, en uzun süre yaşanılan yer, algılanan gelir düzeyi, çocuk sahibi olma durumu, çocuk hakları konusunda eğitim almış olma durumu ve eğitim alma isteğidir. Veri toplama işlemi araştırmacılar tarafından literatür taranarak oluşturulan anket formu aracılığıyla yapılmıştır. Çocuk hakları ile ilgili bilgi durumunun belirlenebilmesi amacıyla katılımcılara çocuk hakları tanımı, çocuk yaş sınırı, çocuk hakları sözleşmesini duyma durumu ve Türkiye'nin bu sözleşmeyi imzalama durumu sorgulanmıştır. Çocuk haklarına yönelik tutumun değerlendirilmesi amacıyla 2006 yılında Karaman Kepenekçi tarafından geliştirilen 22 soruluk Çocuk Haklarına Illişkin Tutum Ölçeği kullanılmıştır (Cronbach alfa=0,85) [7]. Bu çalışmada ise Çocuk Haklarına İlişkin Tutum Ölçeği'nin iç tutarlılığı (Cronbach alfa) 0,796 olarak saptanmıştır. Ölçek beşli derecelendirme sisteminde olup en az 22 en fazla 110 puan alınmakta; alınan puanın yüksek olması çocuk haklarına ilişkin olumsuz tutumu göstermektedir. Katıımcıların sağlık hizmeti sunumu sırasındaki davranışlarını belirlemek amacıyla beşli derecelendirme sisteminde literatür taranarak oluşturulan 11 soru sorulmuş, verilen cevaplara göre davranış puanı hesaplanmıştır. En az 11, en fazla 55 alınabilen bu sorulardan alınan puanın yüksek olması çocuk haklarına ilişkin olumlu davranışı göstermektedir. Çocuk Haklarına llişsin Davranış Ölçeği'nin iç tutarlıı̆̆ (Cronbach alfa) 0,785 olarak saptanmıştır. Çalışma öncesinde etik kurul ve gerekli kurumsal izinler ile katıımcıların sözlü onamları alınmıştır. Verilerin 
değerlendirilmesinde SPSS 17.0 paket programı kullanılmış olup; tanımlayıcı istatistikler için sayı, yüzde, ortalama, standart sapma, ortanca ve çeyrekler arası fark verilmiştir. Bağımsız grup ortancalarının karşılaştırılmasında Mann-Whitney $U$ ve Kruskal-Wallis testleri kullanılmıştır. Çocuk haklarına ilişkin tutum ve davranışlarla ilişkili bağımsız faktörlerin belirlenmesi için çoklu doğrusal regresyon analizi (backward) kullanılmıştır. İstatistiksel anlamlılık düzeyi $p<0,05$ kabul edilmiştir.

\section{Bulgular}

Araştırmaya 83 (\%72) intern hekim ve 140 (\%68) araştırma görevlisi hekim olmak üzere toplamda 223 kişi katılmıştır (\%69). Çalışmaya katılan kişilerin yaş ortalaması $26,8 \pm 3,0$ olup, \%52,7'si erkektir. Katılımcıların \%10,4'ü çocuk sahibidir (Tablo 1).

Katılımcıların \%67,7'si çocuk hakları konusunda eğitim almadığını, \%89,2'si bu konuda eğitim almak istediğini, \%79,7'si kendini çocuk hakları savunuculuğunda yeterli görmediğini belirtmiştir. Çocuk Haklarına Dair Sözleşme'yi duymama sıklığı \%45,5 ve Türkiye'nin bu sözleşmeyi imzaladığını bilmeme sıklığı \%36,8'dir. Katılımcıların \%37,7'si çalışma hayatında çocuk haklarına aykırı muameleye şahit olduğunu ve \%92,8'i kendi çalışma yaşamında çocuk haklarını gözettiğini belirtmiştir (Tablo 2).

Katılımcıların çocuk haklarına ilişkin tutum puan ortalaması $29,8 \pm 7,8$ ve davranış puan ortalaması $46,2 \pm 4,5$ 'tir. İntern hekimlerin ÇHTÖ puan ortalaması 27,6 $\pm 7,3$ ve araştırma görevlilerin puan ortalaması $31,1 \pm 7,7$ olarak bulunmuş olup aradaki fark istatistiksel olarak anlamlıdır $(p<0,001)$. Çocuk hakları ile ilgili eğitim alanların almayanlara göre ve eğitim alma isteği olanların olmayanlara göre ÇHTÖ puanı daha olumludur ( $p=0,03, \quad p=0,045)$. ÇHS'yi duyanların puan ortalaması $27,9 \pm 6,9$, duymayanların puan ortalaması $31,8 \pm 8,2$ olup aradaki fark istatistiksel olarak anlamlıdır $(p<0,001)$. Davranış puan ortalaması intern hekimlerde araştırma görevlisi hekimlere göre ve ÇHS'yi duyanlarda duymayanlara göre daha yüksektir ( $p=0,001, p<0,001)$ (Tablo 3).

Araştırma görevlisi hekimlerin intern hekimlere göre $(p=0,003)$ ve ÇHS'yi duymayanların duyanlara göre $(p<0,001)$ daha olumsuz tutumda olduğu saptanmıştır. Benzer şekilde davranış da araştırma görevlisi hekimlerde intern hekimlere göre $(p<0,001)$ ve ÇHS'yi duymayanlarda duyanlara göre $(p<0,001)$ daha olumsuzdur (Tablo 4).

\section{Tartışma}

Çocuk haklarına ilişkin bilgi, tutum ve davranışın değerlendirilmesi amacıyla yapılan çalışmamızda çocuk haklarına yönelik tutum ve davranışın olumlu olduğu saptanmıştır. Hemşirelik yüksekokulu öğrencilerinin çocuk hakları konusundaki tutumlarının Çocuk Hakları Tutum Ölçeği ile değerlendirildiği bir araştırma sonucunda çalışmamıza benzer olarak katılımcıların ölçek puan ortalaması 29,8 $\pm 12,2$ olarak saptanmıştır [8]. 2012 yılında Kurt [9] tarafından sağlık profesyonellerinin çocuk haklarına ilişkin, bilgi ve tutumlarının değerlendirildiği bir çalışmada da katılımcıların tutumlarının çalışmamıza benzer olarak olumlu olduğu saptanmıştır. Karaman Kepenekci ve ark. [7] yürüttükleri çalışmada ÇHTÖ puan ortalamalarının Zihinsel Engelliler Öğretmenliği Programı için 31,1, Sınıf Öğretmenliği Programı için 27,6, Okul Öncesi Öğretmenliği Programı için 27,6 ve Bilgisayar ve Öğretim Teknolojileri Eğitim Programı için 31,3 olarak açıklamış, genel olarak öğrencilerin çocuk haklarına karşı olumlu tutumda olduğu belirtilmiştir. Son yıllarda insan hakları ve hasta hakları kavramının yaygınlaşmasına bağlı olarak gündeme daha sık gelen çocuk hakları katılımcılarda olumlu tutumun görülmesindeki belirleyicilerden biri olabilir. 
Tablo 1. Katıımcıların sosyodemografik özellikleri.

\begin{tabular}{|c|c|c|}
\hline \multirow{2}{*}{$\begin{array}{l}\text { Yaş (Ort } \pm \mathrm{SS} \text { ) } \\
\text { Değişkenler }\end{array}$} & \multicolumn{2}{|c|}{$26,8 \pm 3,0$} \\
\hline & $\mathbf{n}$ & $\%$ \\
\hline \multicolumn{3}{|l|}{ Cinsiyet $^{*}$} \\
\hline Kadın & 105 & 47,3 \\
\hline Erkek & 117 & 52,7 \\
\hline \multicolumn{3}{|l|}{ Hekim } \\
\hline İntern & 83 & 37,2 \\
\hline Araştırma görevlisi & 140 & 62,8 \\
\hline \multicolumn{3}{|l|}{ Meslekteki yıl $(n=139)^{*}$} \\
\hline 1 & 29 & 20,9 \\
\hline 2 & 38 & 27,3 \\
\hline 3 & 24 & 17,3 \\
\hline 4 & 18 & 12,9 \\
\hline 5 ve üzeri & 30 & 21,6 \\
\hline \multicolumn{3}{|l|}{ Medeni durum* } \\
\hline Evli & 61 & 27,5 \\
\hline Bekar & 161 & 72,5 \\
\hline \multicolumn{3}{|l|}{ Çocuk sahibi olma durumu* } \\
\hline Var & 23 & 10,4 \\
\hline Yok & 199 & 89,6 \\
\hline \multicolumn{3}{|c|}{ En uzun süre yaşanılan yer* } \\
\hline İ & 164 & 74,2 \\
\hline İlçe & 51 & 23,1 \\
\hline Köy & 6 & 2,7 \\
\hline \multicolumn{3}{|l|}{ Algılanan gelir düzeyi } \\
\hline Yeterli & 76 & 34,1 \\
\hline Orta düzeyde yeterli & 133 & 59,6 \\
\hline Yetersiz & 14 & 6,3 \\
\hline
\end{tabular}

*Araştırmaya toplam 223 kişi katılmış olup yanıtlanmayan sorular olması nedeniyle değişkenlerde sayısal farklılıklar bulunmaktadır. 
Tablo 2. Katıımcıların çocuk haklarına ilişkin sorulara verdiği yanıtların dağılımı.

\begin{tabular}{|c|c|c|}
\hline Değişkenler & $\mathbf{n}$ & $\%$ \\
\hline \multicolumn{3}{|c|}{ Çocuk hakları ile ilgili eğitim almış olma } \\
\hline Evet & 72 & 32,3 \\
\hline Hayır & 151 & 67,7 \\
\hline \multicolumn{3}{|c|}{ Çocuk hakları ile ilgili eğitim alma isteği } \\
\hline Evet & 199 & 89,2 \\
\hline Hayır & 24 & 10,8 \\
\hline \multicolumn{3}{|c|}{ Kendini çocuk hakları savunuculuğunda yeterli görme* } \\
\hline Evet & 45 & 20,3 \\
\hline Hayır & 177 & 79,7 \\
\hline \multicolumn{3}{|c|}{ Çocuk yaş sınırını doğru bilme durumu } \\
\hline Evet & 202 & 90,6 \\
\hline Hayır & 21 & 9,4 \\
\hline \multicolumn{3}{|c|}{ Çocuk Haklarına Dair Sözleşme'yi duyma durumu* } \\
\hline Evet & 121 & 54,5 \\
\hline Hayır & 101 & 45,5 \\
\hline \multicolumn{3}{|c|}{ Türkiye'nin Çocuk Haklarına Dair Sözleşme'yi imzaladığını bilme durumu $(n=121)^{*}$} \\
\hline Evet & 74 & 63,2 \\
\hline Hayır & 2 & 1,7 \\
\hline Fikrim yok & 41 & 35,1 \\
\hline \multicolumn{3}{|c|}{ Sağlık çalışanlarının çocuk hakları konusunda aktif rol almadığını düşünme } \\
\hline Evet & 211 & 94,6 \\
\hline Hayır & 7 & 3,1 \\
\hline Fikrim yok & 5 & 2,2 \\
\hline \multicolumn{3}{|c|}{ Sağlık hizmetleri sunumunda çocuk haklarına saygı gösterilmediğini düşünme } \\
\hline Evet & 71 & 31,8 \\
\hline Hayır & 101 & 45,3 \\
\hline Fikrim yok & 51 & 22,9 \\
\hline \multicolumn{3}{|c|}{ Çocukken sağlık hizmetlerinde haklarına saygı gösterilmediğini düşünme } \\
\hline Evet & 87 & 39,0 \\
\hline Hayır & 76 & 34,1 \\
\hline Fikrim yok & 60 & 26,9 \\
\hline \multicolumn{3}{|c|}{ Çalışma hayatında çocuk haklarına aykırı muameleye şahit olma } \\
\hline Evet & 84 & 37,7 \\
\hline Hayır & 118 & 52,9 \\
\hline Fikrim yok & 21 & 9,4 \\
\hline
\end{tabular}


Tablo 2. Katıımcıların çocuk haklarına ilişkin sorulara verdiği yanıtların dağılımı. (devamı)

\begin{tabular}{lcc}
\hline Kendi çalışma yaşamında çocuk haklarını gözetme* $^{*}$ & 206 & 92,8 \\
Evet & 6 & 2,7 \\
Hayır & 10 & 4,5 \\
Fikrim yok
\end{tabular}

*Araştırmaya toplam 223 kişi katılmış olup yanıtlanmayan sorular olması nedeniyle değişkenlerde sayısal farklılıklar bulunmaktadır.

Tablo 3. Katılımcıların çocuk haklarına ilişkin tutumunu (ÇHTÖ) ve sağlık hizmeti sunumları sırasındaki çocuk haklarına yönelik davranışlarını (Davranış Puanı) etkileyen faktörler.

\begin{tabular}{|c|c|c|c|c|}
\hline Değişkenler & $\begin{array}{l}\text { ÇHTÖ Puanı } \\
\text { (Ort } \pm \text { SS) }\end{array}$ & $p$ değeri & $\begin{array}{l}\text { Davranış Puanı } \\
\text { (Ort } \pm \text { SS) }\end{array}$ & $p$ değeri \\
\hline \multicolumn{5}{|l|}{ Yaş } \\
\hline $\begin{array}{l}25 \text { yaş altı } \\
26-30\end{array}$ & $\begin{array}{l}28,21 \pm 7,21 \\
30,53 \pm 8,28\end{array}$ & 0,003 & $\begin{array}{l}47,21 \pm 4,43 \\
45,57 \pm 4,60\end{array}$ & 0,042 \\
\hline 31 ve üzeri & $32,78 \pm 6,29$ & & $46,88 \pm 3,62$ & \\
\hline \multicolumn{5}{|l|}{ Cinsiyet } \\
\hline Kadın & $29,93 \pm 7,51$ & 0,531 & $46,40 \pm 4,23$ & \multirow[t]{2}{*}{0,948} \\
\hline Erkek & $29,65 \pm 8,11$ & & $46,19 \pm 4,79$ & \\
\hline \multicolumn{5}{|l|}{ Hekim } \\
\hline İntern & $27,62 \pm 7,39$ & $<0,001$ & $47,51 \pm 4,42$ & \multirow[t]{2}{*}{0,001} \\
\hline Araştırma görevlisi & $31,15 \pm 7,77$ & & $45,58 \pm 4,43$ & \\
\hline \multicolumn{5}{|l|}{ Meslekteki yıl } \\
\hline $1-2$ yıl & $30,46 \pm 7,52$ & 0,371 & $45,24 \pm 4,94$ & \multirow[t]{2}{*}{0,590} \\
\hline 3 yıl ve üzeri & $31,78 \pm 8,06$ & & $45,92 \pm 3,95$ & \\
\hline \multicolumn{5}{|c|}{ Çocuk sahibi olma durumu } \\
\hline Var & $31,96 \pm 7,75$ & 0,115 & $45,86 \pm 3,73$ & \multirow[t]{2}{*}{0,507} \\
\hline Yok & $29,58 \pm 7,81$ & & $46,31 \pm 4,60$ & \\
\hline \multicolumn{5}{|c|}{ En uzun süre yaşanılan yer } \\
\hline Kır & $31,35 \pm 8,21$ & 0,090 & $45,56 \pm 4,85$ & \multirow[t]{2}{*}{0,159} \\
\hline Kent & $29,35 \pm 7,64$ & & $46,58 \pm 4,40$ & \\
\hline \multicolumn{5}{|l|}{ Eğitim alma durumu } \\
\hline Evet & $28,46 \pm 7,77$ & 0,031 & $46,84 \pm 4,99$ & \multirow[t]{2}{*}{0,087} \\
\hline Hayır & $30,45 \pm 7,77$ & & $46,04 \pm 4,27$ & \\
\hline \multicolumn{5}{|l|}{ Eğitim alma isteği } \\
\hline Evet & $29,62 \pm 7,93$ & 0,045 & $46,31 \pm 4,57$ & \multirow[t]{2}{*}{0,723} \\
\hline Hayır & $31,55 \pm 6,46$ & & $46,16 \pm 4,13$ & \\
\hline
\end{tabular}


Tablo 3. Katılımcıların çocuk haklarına ilişkin tutumunu (ÇHTÖ) ve sağlık hizmeti sunumları sırasındaki çocuk haklarına yönelik davranışlarını (Davranış Puanı) etkileyen faktörler. (devamı)

Çocuk Haklarına Dair

Sözleşme'yi duyma durumu

\begin{tabular}{|c|c|c|c|}
\hline Evet & $27,99 \pm 6,92$ & $<0,001$ & $47,39 \pm 4,45$ \\
\hline Hayır & $31,89 \pm 8,29$ & & $45,14 \pm 4,12$ \\
\hline
\end{tabular}

Kendini savunuculukta yeterli görme durumu

\begin{tabular}{|c|c|c|c|c|}
\hline Evet & $29,80 \pm 7,83$ & 0,931 & $46,46 \pm 5,31$ & 0,584 \\
\hline Hayır & $29,82 \pm 7,85$ & & $46,27 \pm 4,31$ & \\
\hline
\end{tabular}

Tablo 4. Çocuk haklarına ilişkin tutumu etkileyen faktörlerle ilgili regresyon modeli*.

\begin{tabular}{lllllll}
\hline \multirow{2}{*}{ Değişkenler } & \multicolumn{3}{c}{ Çocuk Haklarına İlişkin Tutum } & \multicolumn{4}{c}{ Çocuk Haklarına İlişkin Davranış*** } \\
& B & \%95 GA & $\boldsymbol{p}$ & B & \%95 GA & p \\
\hline Araştırma görevlisi hekim & 3,21 & $1,12-5,30$ & 0,003 & $-2,88$ & $-4,45-(-1,32)$ & $<0,001$ \\
$\begin{array}{l}\text { Çocuk Haklarına Dair } \\
\text { Sözleşme'yi duymayanlar }\end{array}$ & 3,50 & $1,47-5,54$ & 0,001 & $-2,17$ & $-3,32-(-1,01)$ & $<0,001$ \\
\hline
\end{tabular}

* Çocuk haklarına ilişkin tutum puanın yüksek olması çocuk haklarına ilişkin olumsuz tutumu göstermektedir. Fakat çocuk haklarına ilişkin davranış puanının yüksek olması çocuk haklarına ilişkin olumlu davranışı göstermektedir.

**Modele yaş, cinsiyet, meslekteki kıdem durumu, çocuk hakları ile ilgili eğitim almış olma durumu, eğitim alma isteği, Çocuk Haklarına Dair Sözleşme'yi duyma durumu dahil edilmiş olup Lineer Regresyon Analizi yapıımıştır.

***Modele yaş, cinsiyet, meslekteki kıdem durumu, Çocuk Haklarına Dair Sözleşme'yi duyma durumu dahil edilmiş olup Lineer Regresyon Analizi yapılmıştır.

Çalışmamızda literatürde yer alan çalışmalardan farklı olarak çocuk haklarına yönelik tutumla birlikte intern ve araştırma görevlisi hekimlerin sağlık hizmeti sunumları sırasındaki çocuk haklarına ilişkin davranışları da değerlendirilmiş olup katılımcıların olumlu davranış sergilediği belirlenmiştir. Ancak bu değerlendirmenin geçerlilik ve güvenirliliği gösterilmiş bir ölçek ile yapılmamış olması ve yanıtların beyana dayalı olması kısıtlıığı göz önüne alınmalıdır.

Çalışmamızda intern hekimlerinin tutum ve davranışları araştırma görevlilerine göre daha iyi saptanmış olup, bu durum intern hekimler arasında çocuk haklarıyla ilgili eğitim almış olma sıklığının daha fazla olmasından kaynaklanıyor olabilir. Katılımcıların yarısının Çocuk Haklarına Dair Sözleşme'yi duymadığı, sözleşmeyi duymayanların tutum ve davranışlarının daha kötü olduğu saptanmıştır. Kurt'un [9] çalışmasında çalışmamıza göre daha iyi sonuçlar elde edilmiş olup; katılımcıların yaklaşık dörtte üçünün sözleşmeyi duyduğu, intern hekimlerde bu sayının daha fazla olduğu gözlemlenmiş, bu fark intern hekimlerin aldıkları derslere bağlanmıştır. Çocuk haklarının temeli olan ve her bireyin bilmesi gereken bu sözleşmeyi bilme durumunun düşük saptanması eğitim müfredatındaki eksikliği göstermektedir. Nitekim çalışmamızda da katıımcıların sadece üçte birinin çocuk hakları konusunda eğitim aldığı, eğitim alanlarının tutumlarının iyileştiği, kendini çocuk hakları savunuculuğunda daha yeterli gördüğü saptanırken davranış puanında fark olmadığı saptanmıştır. Bu bulgu verilen eğitimin içselleştirilerek davranışa dönüştürülmesi için verilen eğitimlerin yapılandırılması gerekliliğinden kaynaklanıyor olabilir.

Sonuç olarak, intern hekimlerin ve araştırma görevlisi hekimlerin çocuk haklarına ilişkin tutum ve davranışları olumlu olmakla birlikte, ÇHS farkındalığı düşüktür. Eğitim alanlarda tutum ve davranışın daha iyi olmasına karşın katıımcılar arasında eğitim alma sıkığının düşük olması bu konudaki ihtiyacı göstermektedir. Özellikle sağlık personelinin hizmet sunumu sırasında çocuk haklarına ilişkin davranışlarının değerlendirildiği araştırma sayısı kısıtlı olup ileri araştırmalara intiyaç bulunmaktadır.

Çıkar ilişkisi: Yazarlar herhangi bir çıkar ilişkileri bulunmadığını beyan eder. 


\section{Kaynaklar}

1. T.C. Aile ve Sosyal Politikalar Bakanlığı. Ulusal Çocuk Hakları Strateji Belgesi ve Eylem Planı 2013-2017. Erişim adresi: https://ailevecalisma.gov.tr/uploads/ chgm/uploads/pages/yayinlar/ulusal-cocuk-haklaristrateji-belgesi-ve-eylem-plani.pdf. Erişim tarihi 06 Ağustos 2019

2. UNICEF. Çocuk Hakları ve Gazetecilik Uygulamaları. Hak Temelli Perspektif. Erişim adresi: http://www.unicef. org.tr/files/bilgimerkezi/doc/Cocuk\%20Haklari\%20 ve\%20Gazetecilik.pdf. Erişim tarihi 06 Ağustos 2019

3. UNICEF. Sayılarla Dünya Çocuklarının Durumu 2014. Erişim adresi: http://www.unicef.org.tr/files/ bilgimerkezi/doc/Unicef\%20SOWC\%202014\%20web. pdf. Erişim tarihi 06 Ağustos 2019

4. Uluslararası Çocuk Hakları ve Gelişimi Kurumu. Sağlık Çalışanları İçin CRED_PRO Çocuk Hakları Müfredatı. Erişim adresi: http://www.cocukhaklariizleme.org/ wp-content/uploads/CREDPRO-Saglik-Mufredat.pdf. Erişim tarihi 19 Ağustos 2019

5. Waterston T, Goldhagen J. Why children's rights are central to international child health. Arch Dis Child 2006;92:176-180. https://dx.doi.org/10.1136/ adc.2006.098228

6. Worthington R. Standards of healthcare and respecting children's rights. J R Soc Med 2006;99:208-210. https:// dx.doi.org/10.1258/jrsm.99.4.208

7. Karaman Kepenekci $Y$, Baydık B. Zihin engelliler öğretmen adaylarının çocuk haklarına ilişkin tutumları. Ankara Üniversitesi Eğitim Bilimleri Fakültesi Dergisi 2009;42:329-350. https://doi.org/10.1501/ Egifak_0000001150

8. Aldemir E. Hemşirelik Yüksekokulu Öğrencilerinin Çocuk Hakları Konusundaki Tutumlarının Belirlenmesi (Doktora Tezi). İstanbul Bilim Üniversitesi,2014

9. Kurt G. Yataklı Sağlık Kuruluşlarında Çocuk ile ilgili Sağlık Hizmetlerinin Çocuk Hakları Sözleşmesine Uygunluğunun ve Sağlık Profesyonellerinin Çocuk Hakları Konusundaki Farkındalık ve Tutumlarının Değerlendirilmesi (Tıpta Uzmanlık Tezi). Kırıkkale Üniversitesi, 2012

Bu çalışma International Society for Social Pediatrics and Child Health (ISSOP) Kongress, Bonn, Almanya, Kasım 2018 tarihinde poster bildiri olarak sunulmuştur.

Bu çalışma Pamukkale Üniversitesi Bilimsel Araştırma Projeleri Koordinasyon Birimi'nin 2018KRM002-057 nolu kararı ile desteklenmiştir.
Teşekkür: Katkılarından dolayı intern doktorları Ayşegül Atçeken, Burak Can, Süleyman Sencer Çelik, Ceyda Gökcen, Soner Güldaş, Z. Sümeyye Kalkan, Hatice Selma Karaçalık, Muhammet Özgül, Burak Tosuncuk ve Filiz Yılmaz'a teşekkürlerimizi sunarız.

Etik onayı: Pamukkale Üniversitesi Girişimsel Olmayan Klinik Araştırmalar Etik Kurulu'ndan 01.08.2017 tarih ve 10 sayılı ile onay alınmıştır. 